\title{
Using Artificial Neural networks and Optimal Scaling Model to Forecast Agriculture Commodity Price: An Ecological-economic Approach
}

\author{
Roberto Louis Forestal ${ }^{1}$ and Shih-Ming $\mathbf{P i}^{2}$
}

\begin{abstract}
This research paper employs input-output pricing model based on ecologicaleconomic approach to investigate the impacts of internal factors as well as external forces on agriculture commodities. To empirically test our model, we select two different methodologies such as the optimal scaling regression with nonlinear transformations and feedforward artificial neural networks. Our sample includes data related to price of agriculture and energy commodities (cocoa, coffee and crude oil), production of crops and livestock, emissions of greenhouse gases (GHG) from agriculture from 1961 to 2019. Results find a bidirectional relationship between cocoa price and coffee price explaining by the fact that commodity-dependent countries often use kindred production landscapes and similar supply chain management when dealing with coffee and cocoa. Therefore, effect of supply side shocks may be transmitted from one market to another. We also present evidence that greenhouse gas emissions have strong effect on commodity price, thus we encourage an integrated approach including both concrete technological and proactive managerial measures in order to mitigate global warming impacts on the food system. We believe that these findings will be of interest to commodity producers, asset managers and academics who look a better understanding of the dynamics of commodity markets.
\end{abstract}

JEL classification numbers: C50, Q02, Q57.

Keywords: Agriculture commodity, Input-output pricing model, Ecologicaleconomic approach, Artificial neural networks, Optimal scaling regression.

${ }^{1}$ Ph.D. Program in Business, College of Business, Chung Yuan Christian University, Taoyuan City, Taiwan.

${ }^{2}$ College of Business, Chung Yuan Christian University, Taoyuan, Taiwan.

Article Info: Received: March 17, 2021. Revised: March 29, 2021.

Published online: April 6, 2021. 


\section{Introduction}

Comprehending price movement in commodity markets and selecting the appropriate forecasting models have long been the interest of academics and investors. Global trade in agricultural commodities and food has more than doubled between 1995 and 2018, rising from USD 680 billion in 1995 to USD 1.5 trillion in 2018, averaging 7.5 percent share of the total merchandise trade over this period (FAO, 2020). The global cocoa market ranking in the top 10 of global agricultural commodities is expected to grow at an average price of $\$ 2.31$ per kilogram and at a compound annual growth rate of 7.3 per cent from 2019 to 2025 to reach USD 16.32 billion (Voora, Bermúdez, \& Larrea, 2019). However, this growing trend of the food and commodity industry may not last long as those markets remain vulnerable to uncertainty shocks such as the 2008 financial crisis, global climate change and COVID-19 pandemic (Erten \& Ocampo, 2021; Huang, Li, Zhang, \& Chen, 2020). Understanding potential forces and factors that may impact those fluctuations across the above-mentioned markets has several important implications not only for commodity producing firms, but also for asset managers and policy-makers.

A large number of existing studies in the broader literature using several prediction methodologies have examined price volatility of agricultural commodities (Weng et al., 2019; Xiong, Li, \& Bao, 2018). Their results suggest that artificial networks as well as hybrid methods such as mind evolutionary algorithm and support vector machine (MEA-SVM) models generate higher prediction accuracy and faster calculation speed, and therefore may be considered as the most appropriate methods for forecasting agricultural commodity price. In addition, multiple attempts to modelling the effect of oil price on agriculture commodity price have been reported by previous research. They demonstrate how aggregate demand oil price shocks lead to higher non-energy commodity index prices, indicating that the responses of agricultural commodity prices to oil price changes depend greatly on oil-specific shocks (Ahmadi, Behmiri, \& Manera, 2016; Chaudhuri, 2001; Melichar \& Atems, 2019; Wang, Wu, \& Yang, 2014). Moreover, previous studies using numerous methodologies with various strengths have also emphasized on the effects of global warming and climate change on agriculture commodity markets (Akrofi-Atitianti, Ifejika Speranza, Bockel, \& Asare, 2018; Haile, Wossen, Tesfaye, \& von Braun, 2017). They find evidence for significant bidirectional effects in climate changeagriculture commodity relationships, meaning that agriculture products such as cocoa beans are not only exposed to climate change impacts but are also among the main factors responsible for greenhouse gas emissions. Therefore, the authors suggest employing climate smart agriculture as a way to relieve environmental challenges.

The preceding discussion seems to have one common belief that agriculture commodity prices are volatile and may be heavily affected by financial shocks and market uncertainties. Previous studies, however, fails to present a comprehensive analysis on connectedness among driving forces such as social factors, global warming and economic factors that may shape agriculture commodity markets. 
Prior studies do not throw much light on the role of social institution and business cycle on such relationship either. Our contribution to the literature is threefold. First, we systemically identify (Akhtar, Wibe, Simonovic, \& MacGee, 2013; Banerjee, Cicowiez, Horridge, \& Vargas, 2016) factors and constraints that exert influence on human socio-economic activities such production and trade of commodities. Second, we establish the connectedness and spillover effect among commodity markets by integrating ecological-economic approaches into traditional pricing models. Third, we select an input-output framework in order to quantitatively explore the effects of socio-economic and ecological indicators on commodity prices. For that purpose, we have recourse to artificial neural networks and optimal scaling regression and use data related to price and supply of certain commodities and greenhouse gas emissions. Compared to conventional regression models, the use of optimal regression is most appropriate given the fact that the goal of our analysis is to forecast a dependent variable from a set of predictors like the ecological economics approach suggests it (Zhang, Nie, \& Li, 2018).

The remainder of this article is structured as follows. In section 2 we present previous literature relevant to various models used to price and forecast agriculture commodities. The theoretical framework and methodology are presented in section 3 and 4, respectively. Section 5 presents the dataset while the obtained empirical results are discussed in section 6 . The final section 7 concludes the analysis.

\section{Literature review}

The research acknowledges previous studies highlighting the suitability of various methodologies when studying agriculture commodity prices. For instance, Bohl, Siklos, Stefan, and Wellenreuther (2020) use a cost-of-carry model and a linear regression analysis to investigate the relationship among various agricultural commodities. Their dataset includes daily spot and futures prices and futures trading volume relate to two agricultural commodity products (corn and soybeans) and two livestock contracts (live cattle and feeder cattle) for the period starting from January 4, 1993 to June 29, 2018. Findings suggest that speculative activity reduces the level of noise in the futures markets, implying that efforts by regulators to restrain futures speculation could negatively affect the price discovery process in commodity markets. Moreover, Alam and Gilbert (2017) use a structural vector autoregression (VAR) framework to study fluctuations in commodity prices. Their model consider monthly spot prices obtained from United States Department of Agriculture (USDA), the International Monetary Fund Primary Commodity Database, and IndexMundi from 1991 to 2014 and relates to agricultural commodities including banana, barley, beef, cocoa beans, coconut oil and coffee. Their findings show that global economic conditions play an important role in the dynamics of agricultural commodity prices. Moreover, the factor analysis show how that commodities are moving together during a certain period of time. Similarly, adopt a quantile autoregression (QAR) model to investigate the dynamics of agricultural price volatility. The approach is applied to U.S. wheat and corn markets 
over the period of 1980-2017. Additionally, Traoré and Badolo (2016) using autoregressive distributed lag (ARDL) and lag-augmented vector autoregression (LA-VAR) models to study the movement between cocoa and coffee prices found that the long-run elasticity of coffee price with respect to the cocoa one is near to unity, suggesting that the relationship between the two commodities is significant both in the short and long run.

Other methodologies such as artificial neural networks (ANN) and other deep learning models ANN models have proven their precedence over other methods in the work of Weng et al. (2019) comparing back propagation (BP) network method and recurrent neural network (RNN) method to autoregressive integrated moving average (ARIMA) model when forecasting the price of agricultural products. In order to promote better results when forecasting commodity prices, several authors use hybrid methodologies including Xiong et al. (2018) utilizing seasonal-trend decomposition procedures based on loess and extreme learning machines claiming their momentousness for vegetable price forecasting with high seasonality. Similarly, Y. Zhang and $\mathrm{Na}$ (2018) combining the fuzzy information granulation, mind evolutionary algorithm (MEA), and support vector machine (SVM) in order to predict the price of 6 agricultural commodities conclude that the MEA-SVM model was effective and had higher prediction accuracy and faster calculation speed in the forecasting of agricultural commodity price.

Previous research uses umpteen methods to scrutinize the effect of oil price on agriculture commodity price. For instance, Melichar and Atems (2019) use vector autoregressive (VAR) model to delve into the relationship between shocks to the global crude oil market and commodity prices, and whether US renewable energy policy can reshape this relationship. Their dataset consisting of monthly observations is obtained from Energy Information Administration (EIA) for the period starting from January 1980 to December 2015 and includes three energyrelated commodities (coal, crude oil, natural gas) and twenty non-energy commodities such as aluminum, copper, tea and coffee. The real price of oil is deflated by the US Consumer Price Index (CPI). They find evidence that aggregate demand oil price shocks lead to higher energy and non-energy commodity index prices, but a very weak relationship with respect to oil supply and oil-specific demand shocks. They also find evidence of heterogeneity after changes in US energy policy in 2006, with a stronger relationship between oil and other commodity prices. Specifically, oil-specific demand shocks lead to responses of greater magnitude and statistical significance for non-energy commodity indexes. Similarly, structural vector autoregression (SVAR) analysis has been employed to study the impacts of oil price shocks on agricultural commodity markets (Ahmadi et al., 2016; Wang et al., 2014). Their findings indicate that the responses of agricultural commodity prices to oil price changes depend greatly on oil-specific shocks. They also found that oil shocks can explain a minor friction of agricultural commodity price variations before the food crisis in 2006-2008, whereas in post-crisis period their explanatory abilities become much higher. In addition, Chaudhuri (2001) using stationarity and cointegration tests to study the long-run prices of primary 
commodities and oil prices found that real primary commodity prices and real oil prices are cointegrated. They also found that the error in the cointegrating relation stimulates real commodity price adjustment, not real oil price adjustment. Those results tie with the work of Serletis and Xu (2019) applying a four-variable vector error correction (VEC)-GARCH-in-Mean model with a BEKK representation to investigate mean and volatility spillovers between the crude oil market and the main biofuel feedstock markets (corn, soybean, and sugar). The sample uses weekly data related to the above-mentioned four commodities over the period from March 6, 1986 to March 10, 2016. They find that the oil market and the biofuel feedstock markets are tightly interconnected and that the ethanol mandate has strengthened their linkages in terms of volatility spillovers.

Their results also show a strengthening of the relationship between the crude oil market and the biofuel feedstock markets after the introduction of the biofuel policy. On the other hand, Natanelov, Alam, McKenzie, and Van Huylenbroeck (2011), make a combination of different methods including vector error correction model (VECM), Johansen cointegration and two-regime threshold cointegration in order to explore price movements among crude oil futures, agricultural commodities and gold futures. Data are related to monthly futures prices of crude oil, cocoa, coffee, corn, soybeans, soybean oil, wheat, rice, sugar and gold starting July 1989 until February 2010. Their results point out that mature and well established commodity futures markets exhibit co-movement with crude oil in the long run while biofuel policy mitigates the co-movement of crude oil and corn futures until the crude oil prices surpass a certain threshold. In addition, different methods such as augmented autoregressive distributed lag (ARDL) bounds have been used by Zafeiriou, Arabatzis, Karanikola, Tampakis, and Tsiantikoudis (2018) when gauging the relationship between the crude oil and two agricultural commodities (corn, and soybeans). Those authors employed monthly futures prices of the above-mentioned commodities provided by Bloomberg for the period starting from July 1987 until February 2015. Results confirm that crude oil prices affect the prices of agricultural products as well as of ethanol, validating the interaction of energy and agricultural commodity markets. In addition, authors point out that this impact and its implications for the substitution of crude oil with other renewable or non-renewable resources seems to affect the level of carbon emissions and vice versa.

Numerous methodologies with various strengths have also been proposed for modeling the impacts of greenhouse gases emissions on agriculture commodity markets. For example, multivariate linear regression has been used in order to estimate future meat consumption and discusses whether the integration of concentrated animal feeding operation (CAFO) will have environmental impact of this production. Results reveal that total potential greenhouse gas emissions, if all meat were produced in the same method as the US CAFO system and there was no deforestation, would have been 1.3 billion tonnes of $\mathrm{CO} 2$ equivalent in 2000 . Additionally, author claims that if future $\mathrm{CO} 2$ production is to stay at the current amount, meat production accounts for $5.0 \%$ of total production in $2010,5.7 \%$ in 2020 and $6.3 \%$ in 2030 while meat production in the future will still be a large 
producer of greenhouse gases under an expanded CAFO system (Fiala, 2008). Similarly, Haile et al. (2017) also employ a multivariate linear regression to analyze the effect of global climate change on commodity crops (maize, wheat, rice, and soybeans). Their dataset comprising information on country-level commodity production and ending stock is retrieved from Food and Agriculture Organization (FAO) and US Department of Agriculture (USDA) for the period 1961-2013 while data on international market output prices and fertilizer index are obtained from the World Bank's commodity price database. All prices are converted to real 2010 dollar prices by deflating each price with the US Consumer Price Index (CPI). Moreover, the authors construct climate change indicators from variables such as precipitation and temperature obtained from Climatic Research Unit at University of East Anglia. Results found that climate change leads to 1-3\% higher annual fluctuations of global crop production over the next four decades. In addition, they find strong, positive and statistically significant supply response to changing prices for all four crops. However, output price volatility, which signals risk to producers, reduces the supply of these key global agricultural staple crops-especially for wheat and maize. Furthermore, their findings reveal that climate change has significant adverse effects on production of the world's key staple crops, suggesting that combating climate change should employ both mitigation and adaptation technologies. However, studies such as such as Akrofi-Atitianti et al. (2018) and Reay (2019) claim that producing cocoa-related goods is not only exposed to climate change impacts but is also responsible for around 90,000 tonnes of greenhouse gas emissions. Therefore, they advocate a climate smart agriculture way to reduce the sector's GHG emissions and to alleviate the adverse impacts of climate change.

Frank et al. (2017) and Baker et al. (2018) utilize the global biosphere management model (GLOBIOM) to assess the effects of global warming target on agricultural activities. Results show that greenhouse gases have meaningful impacts on crop productivity, total production, and prices. Furthermore, authors find that freer trade can play an important role in helping to buffer regional productivity shocks. Moreover, their findings indicate that efficiency of GHG mitigation will also depend on the level of participation globally. Camanzi, Alikadic, Compagnoni, and Merloni (2017) employ an environmentally extended input-output analysis (EEIOA) and structural path analysis (SPA) to evaluate the impacts greenhouse gas (GHG) emissions throughout the European Union food supply chain. Their dataset retrieving from E3IOT database includes 24 emissions (carbon dioxide, dichloromethane, dinitrogen oxide, etc.) and 11 categories of products (meat; milk, cheese and eggs; fruit; vegetables, etc.) under the classification of individual consumption according to purpose (COICOP). They found that the consumption of meat-related products accounts for more than $35 \%$ of the overall food-related GHG impact while fruits and vegetables are responsible for less than $15 \%$ of total GHGs. Overall, those results suggest an integrated approach in order to achieve effective and efficient GHG mitigation in the food system.

The advantage of our research in comparison with the above studies is the optimal 
scaling model embedded in our ecological pricing model used to predict agriculture commodity trends, while prior studies mostly have recourse to conventional regression models when analyzing commodity markets.

\section{Theoretical framework}

The conceptual framework for this study is based on ecological economics. The core idea of ecological economics is that human economic activity as an open and integrated system is constrained by larger systems of society and the biosphere (Akhtar et al., 2013; Banerjee et al., 2016). Those constraints can be established by social factors (values, institutions) and biosphere's carrying capacity (DanilovDanil'yan \& Reyf, 2018), i.e. its ability to sustain the so called "social metabolism", which is the set of flows of material throughput and energy that occur between natural ecosystems and societies (de Molina \& Toledo, 2014). Environmental factors include biodiversity and ecosystems suggesting that we have an ethical responsibility to promote the richness of human relationships with nature (Spash \& Aslaksen, 2015) while economic factors referring to production capacity and business cycle are important for the understanding of business cycle (Greenwood, Hercowitz, \& Huffman, 1988). Therefore, ecological economics adopting systemic perspective calls upon various fields of study at different levels to acknowledge the intrinsic value of nature when analyzing socio-economic problems as well as environmental challenges faced by modern societies (Bruel, Kronenberg, Troussier, \& Guillaume, 2019; Costanza et al., 2014; Kaufmann \& Cleveland, 1995; Munda, 1997). A particular case refers to the idea of examining the pricing in financial markets in ecological terms. The attempts of Busch, Bauer, and Orlitzky (2016) to explore how financial markets can foster and facilitate more sustainable business practices have stirred up useful discussions (Louche, Busch, Crifo, \& Marcus, 2019; Maltais \& Nykvist, 2020; Schoenmaker \& Schramade, 2018). Sustainable practices imply the existence and operation of infrastructures (transportation and communication), services (health, education, and culture), and institutions (law and policy) that will encourage and support efficient and equitable use of the biosphere resource (Brown, Hanson, Liverman, \& Merideth, 1987). Hence, the necessity to integrate ecological-economic approaches into traditional pricing models is the main focus of this research. 


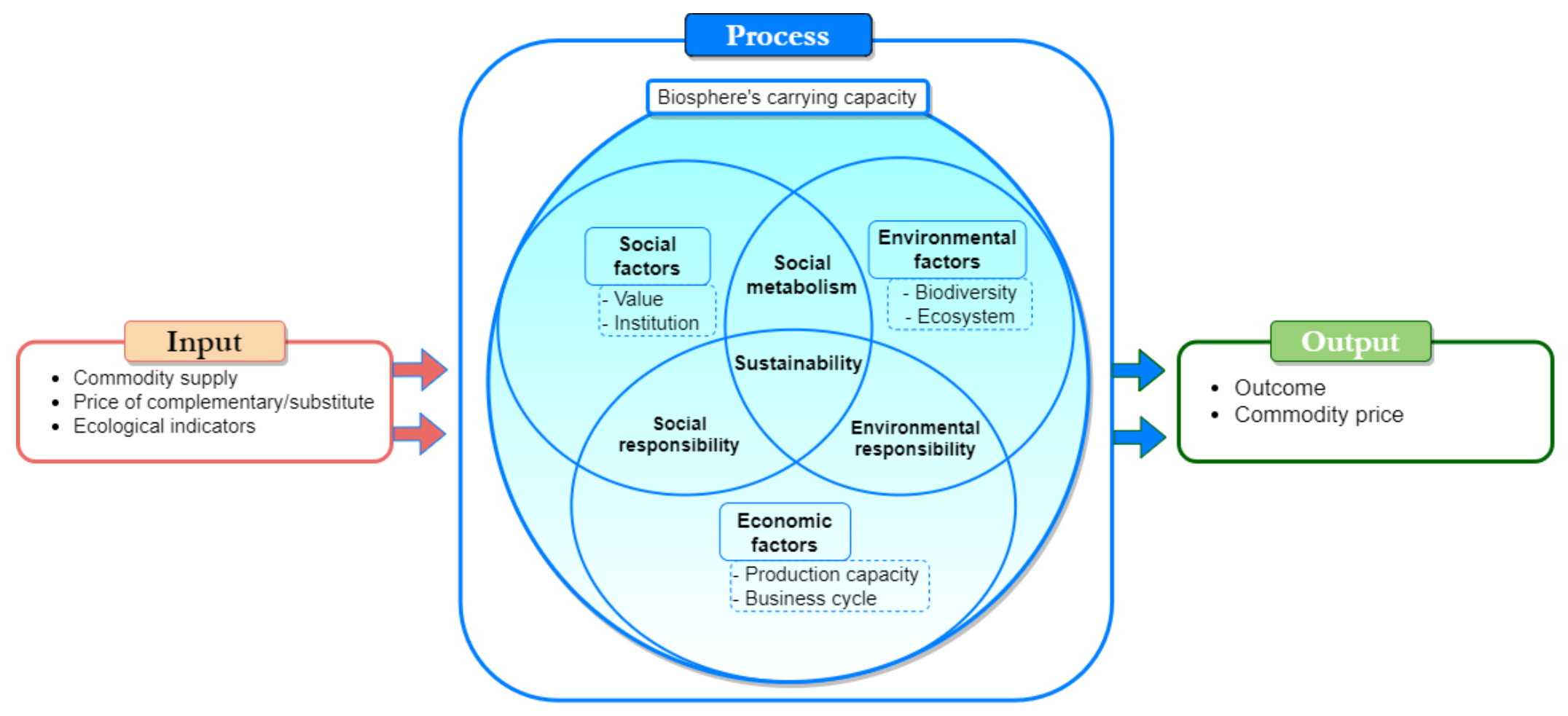

Figure 1: Baseline input-output pricing model embedded in an ecological-economic approach and adapted from Cafuta (2015) 
Since ecological economics is explicitly interdisciplinary in its general approach, it draws upon a large and diverse set of methods, approaches and values, though the extent of admissible or sensible pluralism is debated. For the sake of this paper, we restrict our analysis to the input-output modelling (Leontief, 1987) as it is shown in figure 1. The input-output framework is chosen based on its simplicity, quantitative analysis and data-rich exploratory process. The net input (valued added) of our model contains production of individual commodities, prices of complementary or substitute goods as well as input activities related to socioeconomic metabolism and environmental challenges. On the output side price-related outcomes of the specific commodities are aggregated into one output activity (Hannon, 2001).

\section{Methodology}

We resort to two different methods, namely a computing system (artificial neural networks) and linear regression (optimal scaling regression) to empirically assess variable relationships hypothesized in our input-output model specification.

\subsection{Artificial neural networks}

The idea of an artificial neural network (ANN) dates back to 1940s in the work of McCulloch and Pitts (1943) asserting that neural events and the relations among them can handled by means of propositional logic. Since then, ANNs taking their inspiration from biological neural networks have been employed for several fields of research (Basheer \& Hajmeer, 2000; Chen \& Diaz, 2020; Pi, Liao, Liu, \& Liu, 2011; Sietsma \& Dow, 1991). The main advantage of this method is its ability to portray the non-linear relationship among sets of input-output pairs. This study considers two most popular feedforward artificial neural networks which are MultiLayer Perceptron (MLP) and Radial Basis Function (RBF) networks.

\subsubsection{Multi-Layer Perceptron (MLP)}

Among various types of ANNs, multi-layer perceptron (MLP) is a reliable tool which is designed for the case of this study to predict commodity price following our theoretical framework. It consists an input and an output layer with one hidden layer of nonlinearly-activating nodes (or perceptrons). The response of the hidden layer is the input of the output layer. We use sigmoid function $(\mathrm{Hu}, \mathrm{Hu}, \& \mathrm{Lin}, 2012$; Narayan, 1997) to activate the frequency of action potentials of perceptron.

$$
y=\left(1+e^{-\phi \sum x_{i}}\right)^{-1}
$$

where y represents the dependent variable while xi refer to the predictors; $\phi \in \mathrm{R}$.

Since MLPs are fully connected, we apply the gradient descent method to optimize the weight vector connecting neurons together using back propagation optimization algorithm. The change in each weight can be written following Parlos, Fernandez, Atiya, Muthusami, and Tsai (1994). 


$$
\Delta w_{j i}(n)=-\eta \frac{\partial \varepsilon(n)}{\partial v_{j}(n)} y_{i}(n)
$$

where $\Delta \mathrm{wji}$ is the weight change and $\eta$, the learning rate which is selected to ensure that the weights quickly converge to a response, without oscillations; $\partial \varepsilon(\mathrm{n})$ refers to the node weights while $\partial \mathrm{vj}(\mathrm{n})$ is the induced local field; yi(n) is the output of the previous neuron. Then we minimize the sum-of-squares error between which the actual and the desired network outputs throughout the training period using one consecutive step with no decrease in error as stopping rule (Bishop, 1992). The mean value of the dependent variable is used as the predicted value for each case.

\subsubsection{Radial Basis Function (RBF)}

The Radial Basis Function (RBF) is another popular architecture used in ANN. The $\mathrm{RBF}$, which is also multilayer and feed-forward, is often used for strict interpolation in multi-dimensional space. Like MLP network, the RBF network includes three layers, i.e. input, hidden and output. The input layer is composed of input data while the output layer comprises the outcome. The hidden layer transforms the data from the input space to the hidden space using a non-linear function. We use a normalized radial basis function by computing the Euclidean distance between the input vector and the center of that unit. In the structure of RBF network, the input data, $x$, is a pdimensional vector, which is transmitted to each hidden unit. The activation function of hidden units is symmetric in the input space, and the output of each hidden unit depends only on the radial distance between the input vector, $\mathrm{x}$, and the center for the hidden unit (Bugmann, 1998). Each node in the hidden layer is a pmultivariate Gaussian function following Memarian and Balasundram (2012).

$$
G\left(x^{\prime}, x_{i}\right)=e^{\left[\frac{-1}{2 \sigma_{i}^{2}} \sum_{k=1}^{p}\left(x_{k}-x_{i k}\right)^{2}\right]}
$$

where: $x i$ is the mean (center) and $\sigma_{i}$ is the variance (width). These functions are referred to as radial basis functions. Finally, a linear weight is applied to the output of the hidden nodes to obtain:

$$
F(x)=\sum_{i=1}^{N} w_{i}\left(G\left(x^{\prime}, x_{i}\right)\right)
$$

\subsection{Optimal scaling regression (OSR)}

In addition to ANN methods, we employ the optimal scaling referring to a models that is linear in the parameters, but include nonlinear transformations of the variables. This nonlinear transformation process is known by different names. The term "optimal scaling" was originally coined by Psychometricians in 1960s, but Nishisato (2014) called it dual scaling. The older term optimal scaling is reintroduced to name a method designed to quantify categorical data by assigning numerical values to the categories using optimal scaling method and resulting in an 
optimal linear regression equation for the transformed variables (Fazeli, Hassani, Mondelli, \& Vardy, 2020; Willems, Fiocco, \& Meulman, 2017; R. Zhang et al., 2018). Using nonlinear transformations allow variables to be analyzed at a variety of levels to find the best-fitting model. It is convenient to write the optimization task in the form of a least squares loss function following Meulman, van der Kooij, and Duisters (2019)

$$
L(\beta, \varphi, \vartheta)=\left\|\vartheta(y)-\sum_{k=1}^{p} \beta_{k} \varphi_{k} x_{k}\right\|^{2}
$$

Where \|\|$^{2}$ denotes the squared Euclidean norm. $\vartheta(y)$ refers to transformation of $y$ while $\varphi_{\mathrm{k}} \mathrm{X}_{\mathrm{k}}$ stands for the set of nonlinear transformations of the predictors. $\beta_{\mathrm{k}}$ is the vector of coefficients. Loss function has to be minimized.

We take into account two different kinds of nonlinear transformations which are numerical transformation and quantification nominal. The implication of numerical transformation is that the distances between the category points have to be equal, and the category quantifications will be proportional to the original category numbers. On the other hand, we merely maintain the class membership information in the quantified variable in the nominal transformation (Meulman, Van der Kooij, $\&$ Heiser, 2004). The solution of our categorical regression model ultimately maximizes the squared correlation between the transformed response and the weighted combination of transformed predictors. For that reason, linear and nonparametric correlations have been introduced in the analysis. As a linear correlation statistic, the Pearson correlation coefficient of two variables $\mathrm{X}$ and $\mathrm{Y}$ is formally defined as the covariance of the two variables divided by the product of their standard deviations (which acts as a normalization factor) and it can be equivalently defined by Zhou, Deng, Xia, and Fu (2016):

$$
r_{x y}=\frac{\sum\left(x_{i}-\bar{x}\right) \sum\left(y_{i}-\bar{y}\right)}{\sqrt{\sum\left(x_{i}-\bar{x}\right)^{2}} \sqrt{\sum\left(y_{i}-\bar{y}\right)^{2}}}
$$

Where $\mathrm{x}^{-}$denotes the mean of $\mathrm{x}$. $\mathrm{y}^{-}$denotes the mean of $\mathrm{y}$.

Kendall-tau-b $\left(\tau_{\mathrm{B}}\right)$ which is a non-parametric correlation coefficient is used to assess and test correlations between non-interval scaled ordinal variables. It is a measure of rank correlation: the similarity of the orderings of the data when ranked by each of the quantities. The Kendall tau-b for measuring order association between variables $\mathrm{X}$ and $\mathrm{Y}$ is adapted from Somers (1962):

$$
\tau_{\mathrm{B}}=\frac{C-D}{\sqrt{\left(C+D+X_{0}\right)\left(C+D+Y_{0}\right)}}
$$

where $\mathrm{C}$ is the number of concordant pairs, $D$ is the number of discordant pairs, $\mathrm{X}_{0}$ is the number of pairs tied for $X$ variable, $\mathrm{Y}_{0}$ is the number of pairs tied for $Y$ variable. 


\subsection{Evaluation of the forecasts}

To statistically compare the forecast efficiency from different models, we employ three accuracy criterion namely $\mathrm{R}$ squared $\left(\mathrm{R}^{2}\right)$, mean absolute error (MAE) and root mean square error (RMSE). These statistical criteria are widely employed in commodity market modeling (Black, Klinkowska, McMillan, \& McMillan, 2014; Mahdavi \& Zhou, 1997; Paschke \& Prokopczuk, 2010). Lower RMSE and MAE values indicate the best forecasting methods while the higher value of $\mathrm{R}$ squared reflects the best fitting models. Those measures are calculated as follows:

$$
\begin{array}{r}
R^{2}=1-\frac{\sum_{i=1}^{N}\left(Y_{i_{\text {observed }}}-Y_{i_{\text {predicted }}}\right)^{2}}{\sum_{i=1}^{N}\left(Y_{i_{\text {observed }}}-\bar{Y}_{\text {observed }}\right)^{2}} \\
\text { MAE }=\frac{\mathbf{1}}{\boldsymbol{N}} \sum_{i=1}^{N}\left|\boldsymbol{Y}_{i_{\text {observed }}}-Y_{i_{\text {predicted }}}\right| \\
R M S E=\sqrt{\frac{1}{N} \sum_{i=1}^{N}\left(Y_{i_{\text {observed }}}-Y_{i_{\text {predicted }}}\right)^{2}}
\end{array}
$$

where $\mathrm{Yi}_{\text {observed, }}$ and $\mathrm{Yi}_{\text {predicted }}$ denote the actual and predicted values of the commodity price, respectively. The term $\mathrm{N}$ represents the number of observations in the sample, and $\mathrm{Y}_{\text {observed }}$ stands for the average of the actual values of commodity price.

\section{Data}

Our study considers data coming from publicly available databases World Bank's Pink Sheet and Food and Agriculture Organization (FAO) of the United Nations from 1961 to 2019. We focus on international level of analysis, i-e level price of cocoa bean (cocoa_price), coffee (coffee_price) and crude oil (oil_price), supply of crops and livestock as well as greenhouse gases (GHG) emissions from agriculture (agriemission) involve information related to the whole world. Data on cocoa bean and coffee prices are US dollar-denominated nominal per kilogram while crude oil prices are referenced as dollar per barrel. Crop statistics are computed for over 150 products, covering three categories which are grains (almonds, barley, carobs, cashew nuts, coffee, etc.), fruits (apples, apricots, blueberries, cherries, etc.) and vegetables (artichokes, asparagus, cabbages, turnips, etc.). Livestock data are recorded for three categories of products including meat, eggs and milk. We take an average price for each category before summing up them. Crops and Livestock use billion kilograms as units while GHG emissions from agriculture referring to different agricultural activities such as enteric fermentation, synthetic fertilizers and crop residues are in million gigagrams and. We compute total agriemission as sum of emission from methane (CH4), nitrous oxide (N2O) and carbon dioxide equivalent (CO2eq). IBM SPSS software is used to analyze our data. 
Table 1 describes the sample size and summary statistics of our variables. The average price varies from $\$ 1.715$ per kilogram (cocoa bean) to $\$ 30.564$ per barrel (crude oil) while the average supply of crops $(5401.290 \times 109 \mathrm{~kg})$ is higher than that of livestock $(784.501 \times 109 \mathrm{~kg})$. The greenhouse gases emissions coming from agricultural activities averaged $4.320 \times 106$ gigagrams during the considered sample period. The lowest value of cocoa bean $(\$ 0.365)$ has been reported in 1965 while its largest score $(\$ 3.790)$ has been recorded in 1977 . The price of coffee has fallen to its lowest level $(\$ 0.806)$ in 1963 while its highest price $(\$ 5.976)$ has been reported in 2011. Crude oil shows its lowest price (\$1.210) in 1970 and its highest value (\$105.010) has been computed in 2012. The lowest supply level of crops and livestock has been reported in 1961. Since then, the production of crops and livestock continues to increase annually, reporting their highest values in 2019 . Standard deviations range from 0.872 (cocoa_price) to 1995.379 (crops), meaning that crops distributions have values which are generally farther from their mean compared to other variables in the sample. Skewness describing the asymmetry of the normal distribution shows that all instruments except agriemission are positively skewed. Kurtosis coefficient measuring the peakedness of the distribution imply that variables have leptokurtic distribution (positive excess kurtosis). From the Jarque-Bera test ( $\mathrm{p}$-value $>0.05$ ), the residual normality shows that variables except agriemission and oil_price are normally distributed.

Table 1: Sample Size and summary statistics

\begin{tabular}{|l|c|c|c|c|c|c|}
\hline & $\begin{array}{c}\text { cocoa } \\
\text { price }\end{array}$ & $\begin{array}{c}\text { coffee } \\
\text { price }\end{array}$ & crops $^{\mathbf{a}}$ & livestock $^{\mathbf{a}}$ & agriemission $^{\mathbf{b}}$ & oil price \\
\hline Mean & $\$ 1.715$ & $\$ 2.507$ & 5401.290 & 784.501 & 4.320 & $\$ 30.564$ \\
\hline Minimum & $\$ 0.365$ & $\$ 0.806$ & 2528.776 & 430.648 & 2.844 & $\$ 1.210$ \\
\hline Maximum & $\$ 3.790$ & $\$ 5.976$ & 9348.690 & 1308.731 & 5.501 & $\$ 105.010$ \\
\hline STD & $\$ 0.872$ & $\$ 1.226$ & 1995.379 & 252.186 & 0.965 & $\$ 29.503$ \\
\hline Skewness & 0.363 & 0.387 & 0.458 & 0.487 & -1.472 & 1.194 \\
\hline Kurtosis & 2.302 & 2.634 & 2.115 & 2.192 & 7.388 & 3.508 \\
\hline Jarque-Bera & 2.491 & 1.800 & 3.986 & 3.936 & 68.643 & 14.655 \\
\hline Probability & .288 & .407 & .136 & .140 & .000 & .001 \\
\hline Observations & 59 & 59 & 59 & 59 & 59 & 59 \\
\hline
\end{tabular}

a: Mean, minimum and maximum are expressed in billion kilograms

b: Mean, minimum and maximum are in million gigagrams

STD: Standard deviation

Source: Authors' own computations

\section{Results and discussions}

Table 2 summarizes the linear and non-parametric correlations among variables. Results show that there exist strong parametric and non-parametric relations $(\mathrm{r}=0.858$; tau- $\mathrm{b}=0.695)$ between cocoa_price and coffee_price. This result ties well with Traoré and Badolo (2016) wherein the prices of the commodities were found 
to be cointegrated. The bidirectional link between the price of the two commodities may be the impacts of supply side shocks from one market being transmitted to the other one. We also acknowledge linear and non-parametric correlation between agriemission and cocoa_price $(\mathrm{r}=0.390$; tau- $\mathrm{b}=0.397)$. These basic findings are consistent with Reay (2019) and Akrofi-Atitianti et al. (2018) showing that cocoa farming is largely associated with greenhouse gases emissions. The positive bidirectional relationship means that high temperatures and drought can impact cocoa yields and prices. Likewise, growing cocoa and cocoa by-products may lead to soil degradation, poor yields an increase in agricultural emissions. In addition, cocoa bean price has moderate linear relation with crops $(\mathrm{r}=0.574)$ and livestock $(\mathrm{r}=0.570)$ but gets a weak rank correlation with crops $(\mathrm{tau}-\mathrm{b}=0.435)$ and livestock (tau- $b=0.439$ ), indicating a rather straight-line relationship between those variables. On the other hand, the link between cocoa_price and oil_price is both linear $(\mathrm{r}=0.633)$ and non-parametric (tau- $\mathrm{b}=0.521)$. A similar pattern of results was obtained in Chaudhuri (2001) who found some important linkages between real commodity prices and oil prices in the sense that the magnitude of oil price shocks could affect cocoa beans. Additionally, we find that a moderate linear correlation exists between coffee price and crops $(\mathrm{r}=0.553)$, livestock $(\mathrm{r}=0.545)$ and oil price $(\mathrm{r}=0.614)$ while the Kendall correlation between coffee price and crops (tau$\mathrm{b}=0.399$ ), livestock (tau- $\mathrm{b}=0.405)$, agriemission (tau- $\mathrm{b}=0.393$ ) and oil_price (tau$\mathrm{b}=0.459$ ) translating a dissimilar rank between variables. In addition, high correlation scores $(\mathrm{r}=0.998$; tau- $\mathrm{b}=0.987)$ between crops and livestock mean that the observations of the two variables have identical rank. Similar observations can be reported between crops and oil-price $(\mathrm{r}=0.837$; tau- $\mathrm{b}=0.662)$. Oil-price have both strong ranking relation and high linear relation with agriemission. Therefore, the use of optimal scaling regression would be beneficial to further investigate these behavioral patterns fully. 
Table 2: Correlations among pairs of variables

\begin{tabular}{|c|c|c|c|c|c|c|c|}
\hline & $\begin{array}{c}\text { correlation } \\
\text { coefficient }\end{array}$ & $\begin{array}{c}\text { cocoa } \\
\text { price }\end{array}$ & $\begin{array}{c}\text { coffee } \\
\text { price }\end{array}$ & crops & livestock & $\begin{array}{c}\text { agri } \\
\text { emission }\end{array}$ & $\begin{array}{c}\text { oil } \\
\text { price }\end{array}$ \\
\hline \multirow{2}{*}{ cocoa price } & Pearson & 1.000 & & & & & \\
\hline & Kendall'tau_b & 1.000 & & & & & \\
\hline \multirow{2}{*}{ coffee price } & Pearson & 0.858 & 1.000 & & & & \\
\cline { 2 - 9 } & Kendall'tau_b & 0.695 & 1.000 & & & & \\
\hline \multirow{2}{*}{ livestock } & Pearson & 0.574 & 0.553 & 1.000 & & & \\
\cline { 2 - 9 } & Kendall'tau_b & 0.435 & 0.399 & 1.000 & & & \\
\cline { 2 - 9 } agriemission & Kearson & 0.570 & 0.545 & 0.998 & 1.000 & & \\
\cline { 2 - 9 } & Kendall'tau_b & 0.439 & 0.405 & 0.987 & 1.000 & & \\
\hline & Kearson & 0.390 & 0.441 & 0.601 & 0.589 & 1.000 & \\
\hline \multirow{2}{*}{ oil price } & Pearson & 0.633 & 0.614 & 0.837 & 0.833 & 0.540 & 1.000 \\
\hline & Kendall'tau_b & 0.521 & 0.459 & 0.662 & 0.666 & 0.628 & 1.000 \\
\hline
\end{tabular}

Note: results are all significant at $1 \%$ level

$\mathrm{N}=59$ observations

Source: Authors' own computations

Table 3: Artificial neural network information and model summary

\begin{tabular}{|l|l|r|}
\hline Methods & MLP & RBF \\
\hline Method for Covariates & Normalized & Normalized \\
\hline \multicolumn{2}{|c|}{ Model } \\
\hline \multicolumn{2}{|c|}{ Normalized } & Normalized \\
\hline Training & 0.310 & 0.188 \\
\hline Sum of Squares Error & 0.187 & 0.150 \\
\hline Relative Error & & \\
\hline Testing & 0.171 & 0.085 \\
\hline Sum of Squares Error & 0.196 & 0.137 \\
\hline Relative Error & &
\end{tabular}

Dependent variable: cocoa_price

Covariates: coffee_price; crops; livestock; agriemission; oil_price

MLP: Multilayer Perceptron networks; RBF: Radial Basis Function networks

Source: Authors' own computations

Table 3 outputs information on Artificial neural networks (ANN). We randomly assigned the number of cases relative to the training, testing and holdout. To reduce the network complexity, we follow a single hidden layer architecture. In addition, we use normalization process and autoscaling approach so that outliers do not prevail over the rest of the sample data. This method returns a zero mean and unit variance of any variable (Madhiarasan \& Deepa, 2017). For Multilayer Perceptron (MLP) networks, the sigmoid activation function was implemented in both hidden and output layers given the fact that the algorithm recommended a response function with a continuous and simple derivative form (Mercioni, Tiron, \& Holban, 2019). 
As a result, $63.5 \%$ of the sample were assigned to the training sample, $30.1 \%$ to the testing and $6.4 \%$ were excluded from the analysis due to the presence of outliers. The average overall relative errors are quite constant across training $(0.187)$ and testing (0.196) samples showing that the model is not overtrained. Figure 2 schematically represents the MLP network structures with a total of four units including in the hidden layer. Results also show that input variables are mostly linked to hidden layers' units through negative synaptic weight while the hidden layers are almost positively connected to the dependent variable. To measure predicted values based on the importance of each independent variable, we use a sensitivity analysis as shown in figure 3 . This chart shows that the results are dominated by coffee_price (100\%) and oil_price (68.5\%), followed distantly by agriemission (40.1\%), crops (21.0\%) and livestock (16.6\%). One socio-economic explanation is that coffee and cocoa which are both tropical commodities represent a major source of income for many African countries like Cote-d'Ivoire that have strong commodity-export dependence (Maurice \& Davis, 2011). As a results, coffee price tends to affect the price movement of cocoa in the long run compared to other crops and livestock. In addition, the results of our proposed model can be compared with those of the traditional methods. For instance, our findings are line with previous studies such as Melichar and Atems (2019) and Natanelov et al. (2011) finding evidence that aggregate oil price shocks lead to higher non-energy commodity index prices and confirming that crude oil prices affect the prices of agricultural products.

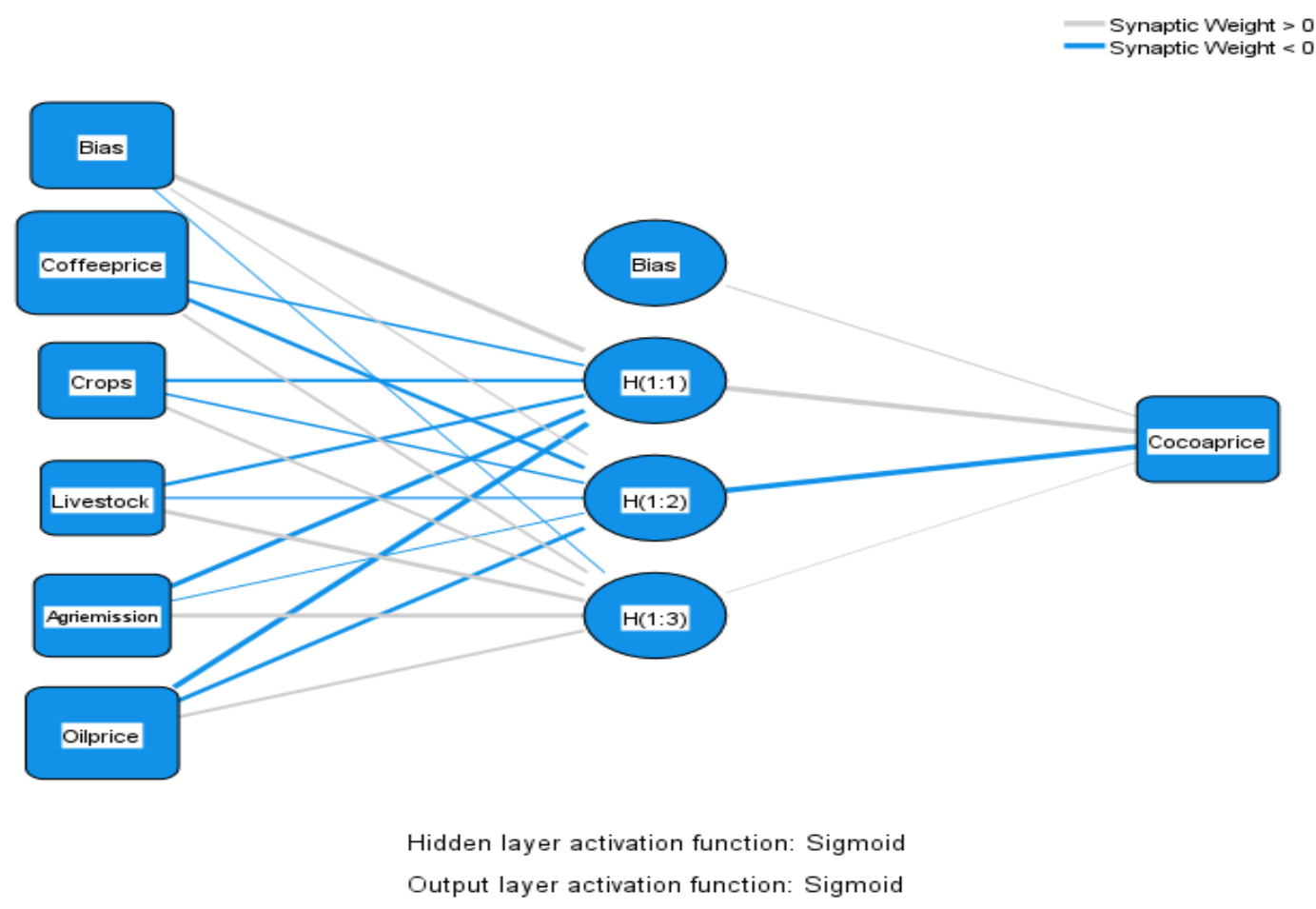

Figure 2: Multilayer Perceptron network structure 


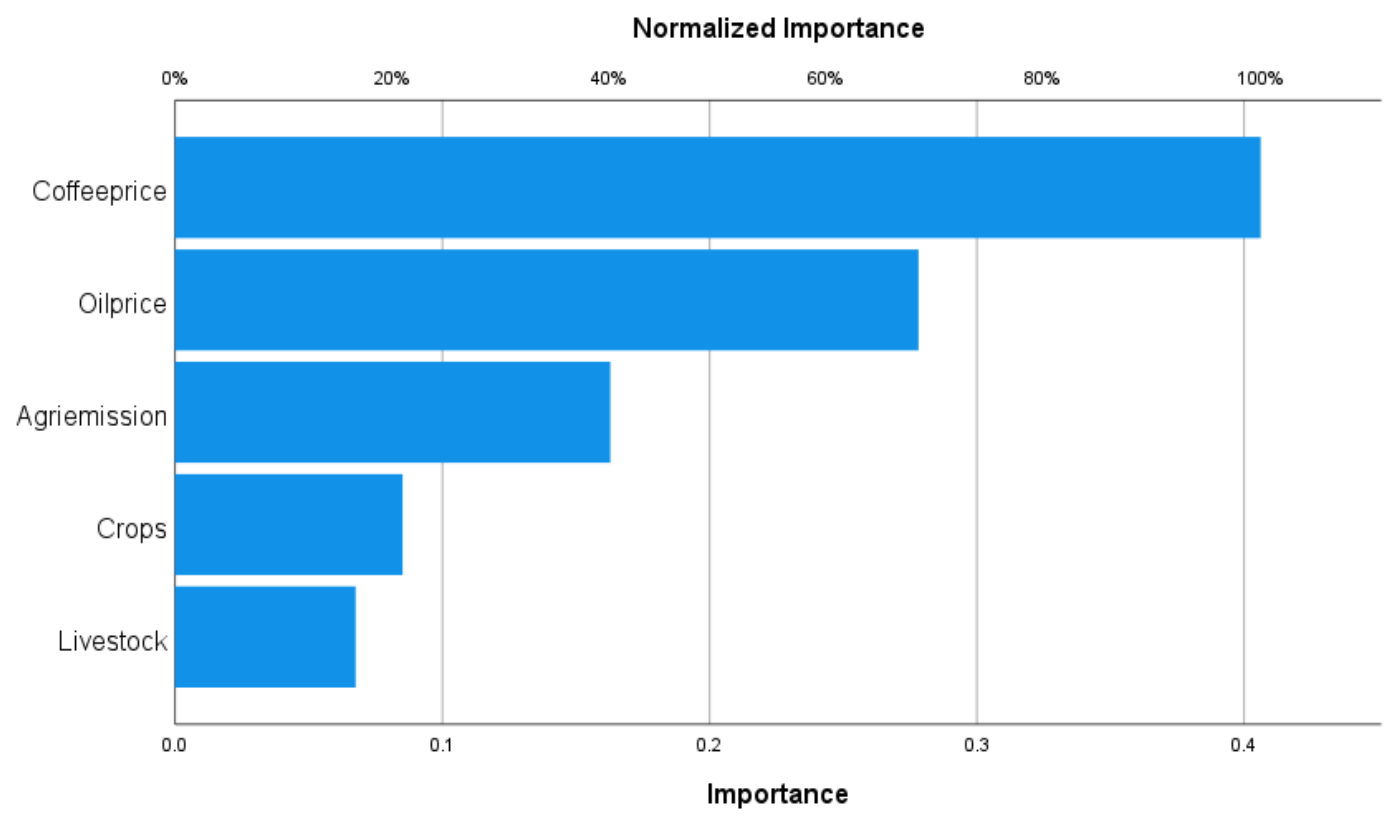

Figure 3: MLP network predictor variable importance chart

As regards radial basis function (RBF), softmax function was used in hidden layers while identity was employed as an activation function in output layers; accordingly, $61.9 \%$ of the cases were distributed to the training sample, $31.7 \%$ to the testing and $6.4 \%$ were rejected. We find that the relative errors are quite constant across in both training (0.150) and testing (0.137) samples suggesting that the overall error recorded by the network in future cases will be close to the one reported here. A schematic representation of the RBF network with a nine-units hidden layer model is given in Figure 4. This figure shows that variables and layers are all connected together via positive synaptic weight. Figure 5 returns the importance of each independent variable in explaining model predicted values and shows coffee_price $(100 \%)$ as the most prominent variable following by agriemission $(89.9 \%)$ and oil_price $(85.2 \%)$. On the environmental plan, coffee and cacao can grow in the same climate and landscapes. Moreover, both crops are hand-harvested to preserve the next harvest because each plant flowers and fruits simultaneously, thus encourage contractors to develop effective supply chain for both products (Vaast, Harmand, Rapidel, Jagoret, \& Deheuvels, 2016). In addition, other results regarding agriemission were broadly in line with previous research demonstrate that greenhouse gases have meaningful impacts on crop prices and suggest an integrated approach in order to palliate the impact of greenhouse gases on the food system (Camanzi et al., 2017; Frank et al., 2017; Haile et al., 2017). 


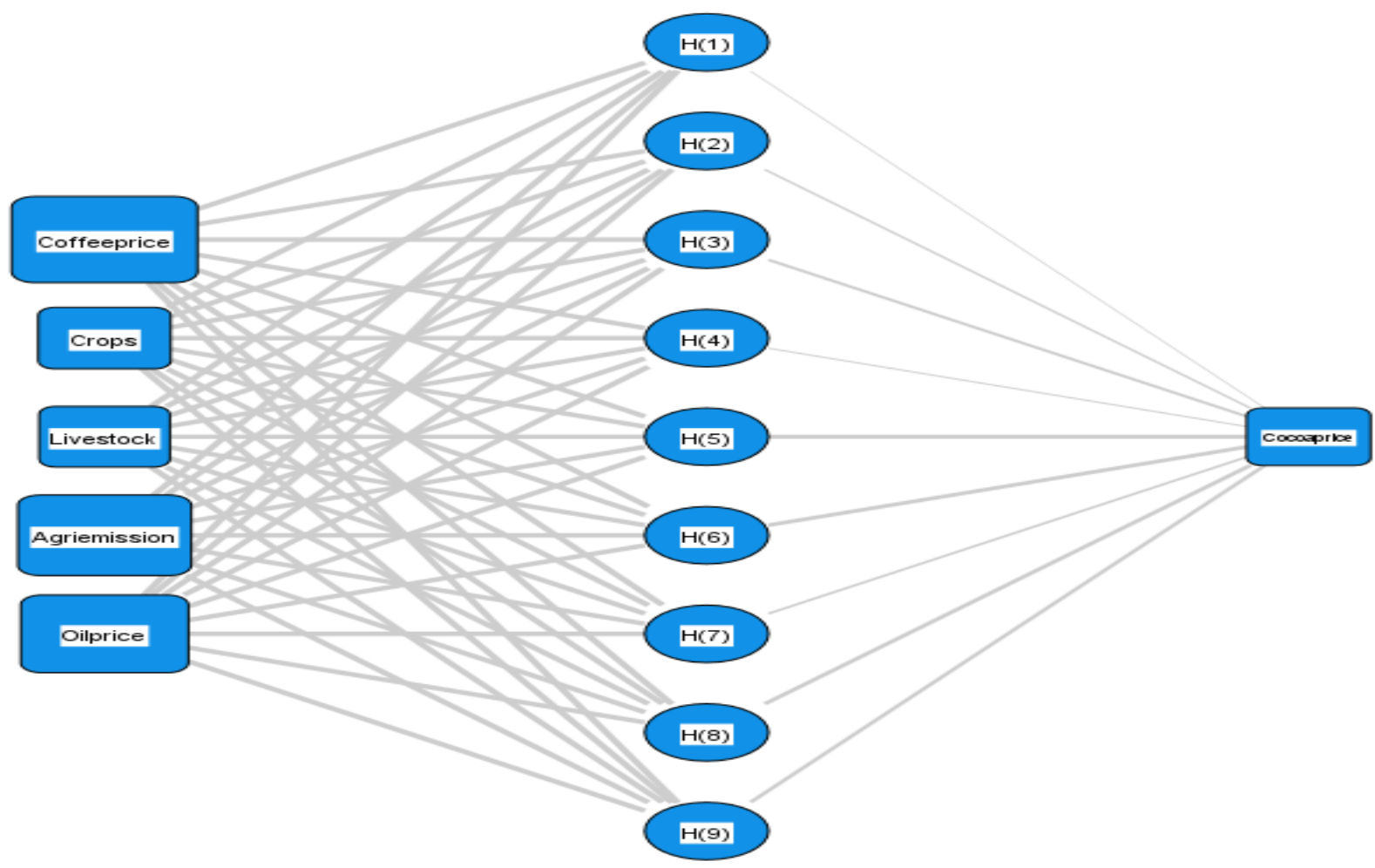

Hidden layer activation function: Softmax Output layer activation function: Identity

Figure 4: Radial Basis Function network structure

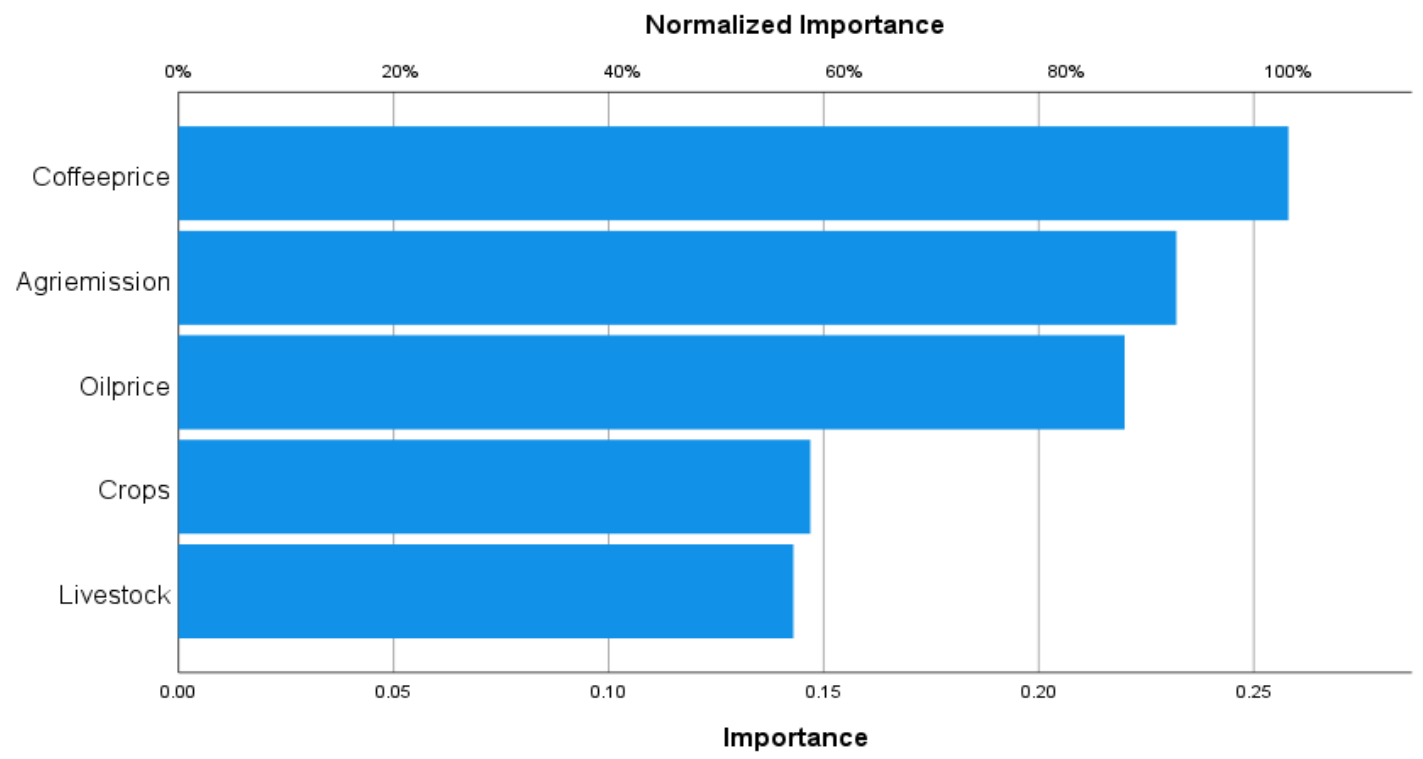

Figure 5: RBF network independent variable importance chart 
Table 4 displays optimal scaling procedures. As in ANN analysis, $6 \%$ of the total observation were excluded due to presence of outliers. Numeral scaling method is used to level the dependent variable while a nominal transformation is employed in the specification of independent variables. Moreover, results return six valid groups for each variable after discretization showing categories starting from 2 to 7 . The only exception is related to agriemission having categorization values starting from 1. It has to be noted that scale values are assigned to each category such that these values are optimal with respect to the regression. Model summary as well as standardized coefficients are reported in Table 5. Beta statistics are all different starting from 0.240 (cofee_price) to 0.453 (livestock). Results highlight that the standard error of the regression coefficients which has been estimated by a bootstrap with 1000 samples and 5 degrees of freedom is fairly constant across the sample. Ftest shows that all predictor variables were statistically significant with p-values being 0.016 or less. Unlike standard linear regression predictors, the value of independent variable in the optimal scaling model are not the scores on the original variables but the quantification of these scores. So the categories of the predictor variables such as coffee_price and agriemission are positive and have almost similar quantified values, thus can be interpreted as having similar positive contribution to the prediction. Moreover, the multiple $\mathrm{R}$ which is the coefficient of multiple correlation between response and the fitted values equals 0.947 while the difference between the test set target and output expressed by the apparent prediction error is 0.104. A similar conclusion was reached by Baker et al. (2018) employing different methodology to study agricultural activities in relation to global warming and suggesting that greenhouse gases have significant effects on cocoa production and price. 
Table 4: Optimal Scaling discretization and categorization

\begin{tabular}{|c|c|c|c|c|c|c|c|c|c|c|c|c|c|c|c|c|c|}
\hline \multicolumn{3}{|c|}{ cocoa_price $^{1}$} & \multicolumn{3}{|c|}{ coffee_price $^{2}$} & \multicolumn{3}{|l|}{ crops $^{2}$} & \multicolumn{3}{|c|}{ livestock $^{2}$} & \multicolumn{3}{|c|}{ agriemission $^{2}$} & \multicolumn{3}{|c|}{ Oil_price $^{2}$} \\
\hline Valid & $\mathbf{C}$ & $\mathbf{F}$ & Valid & $\mathbf{C}$ & $\mathbf{F}$ & Valid & $\mathbf{C}$ & $\mathbf{F}$ & Valid & $\mathbf{C}$ & $\mathbf{F}$ & Valid & $\mathbf{C}$ & $\mathbf{F}$ & Valid & $\mathbf{C}$ & $\mathbf{F}$ \\
\hline$\$ 0.4-\$ 0.9^{a}$ & 2 & 13 & $\$ 0.81-\$ 1.44^{\mathrm{a}}$ & 2 & 18 & $2528.8-3640.9^{a}$ & 2 & 15 & $430.65-563.77^{a}$ & 2 & 15 & .00 & 1 & 1 & $\$ 1.21-\$ 2.81$ & 2 & 13 \\
\hline$\$ 1.07-\$ 1.46$ & 3 & 12 & $\$ 1.45-\$ 1.97$ & 3 & 6 & $3818.3-4820.1$ & 3 & 13 & $575.88-699.95$ & 3 & 10 & $2.84-3.36$ & 2 & 10 & $\$ 10.4-\$ 20.4^{\mathrm{a}}$ & 3 & 18 \\
\hline$\$ 1.54-\$ 1.95$ & 4 & 11 & $\$ 2.29-\$ 2.72$ & 4 & 7 & 5026.4-5933.0 & 4 & 10 & $715.33-835.83$ & 4 & 13 & $3.43-3.98$ & 3 & 11 & $\$ 22.88-\$ 37.73$ & 4 & 13 \\
\hline$\$ 1.99-\$ 2.44$ & 5 & 12 & $\$ 2.87-\$ 3.53^{\mathrm{a}}$ & 5 & 18 & $6070.0-6932.6$ & 5 & 8 & $855.54-997.58$ & 5 & 8 & $4.01-4.30$ & 4 & 8 & $\$ 42.81-\$ 53.39$ & 5 & 4 \\
\hline$\$ 2.58-\$ 3.06$ & 6 & 6 & $\$ 3.59-\$ 4.42$ & 6 & 8 & $7243.1-8213.5$ & 6 & 6 & $1022.9-1156.0$ & 6 & 7 & $4.64-5.06^{\mathrm{a}}$ & 5 & 17 & $\$ 61.41-\$ 71.12$ & 6 & 5 \\
\hline$\$ 3.13-\$ 3.79$ & 7 & 5 & $\$ 5.17-\$ 5.98$ & 7 & 2 & $8607.8-9348.7$ & 7 & 7 & 1189.6-1308.7 & 7 & 6 & $5.14-5.50$ & 6 & 12 & $\$ 79.04-\$ 105.0$ & 7 & 6 \\
\hline Total & & 59 & Total & & 59 & & & 59 & Total & & 59 & Total & & 59 & Total & & 59 \\
\hline
\end{tabular}

1: Optimal Scaling Level: Numerical; 2: Optimal Scaling Level: Nominal; ${ }^{a}$ : Mode; Valid: Valid grouping; C: Category after discretization; F: Frequency

Source: Authors' own computations

Table 5: Optimal scaling model summary

\begin{tabular}{|c|c|c|c|c|c|}
\hline \multicolumn{7}{|c|}{ Standardized Coefficients } \\
\hline & coffee_price & crops & livestock & agriemission & oil_price \\
\hline Beta & 0.240 & 0.379 & 0.453 & 0.258 & 0.447 \\
\hline Estimate of Std. Error ${ }^{1}$ & 0.115 & 0.167 & 0.189 & 0.143 & 0.183 \\
\hline df & 5 & 5 & 5 & 5 & 5 \\
\hline F-test & 4.347 & 5.136 & 5.709 & 3.277 & 5.976 \\
\hline Sig. & .004 & .001 & .001 & .016 & .000 \\
\hline \multicolumn{7}{|c|}{ Standardized Data } \\
\hline \\
\hline \multicolumn{7}{|c|}{0.947} & Adjusted R Squared & $\begin{array}{c}\text { Apparent } \\
\text { Prediction Error }\end{array}$ \\
\hline
\end{tabular}

1: Bootstrap (1000); Dependent Variable: cocoa_price; df: degrees of freedom

Source: Authors' own computations 
Table 6 presents a comparison forecasting accuracy among models, namely Multilayer Perceptron networks (MLP), Radial Basis Function networks (RBF) and Optimal Scaling Regression (OSR) measure of how close the data are to the fitted regression line. $\mathrm{R}$ squared measuring data closeness to the fitted regression line indicates that OSR model explains $89.6 \%$ of the variability of the response data around its mean while the predictors in ANN models explain at most $85.6 \%$ of variance in the dependent variable. Mean absolute error (MAE) capturing the average magnitude of the errors in a set of predictions returns the lowest score (0.270) for RBF and the highest value (1.715) for OSR. A similar conclusion can be reached from the root mean square error (RMSE) measure which is the standard deviation of the residuals. Highest score has been assigned to OSR while results show that RBF has the lowest value. Those results suggest that OSR parameters are good predictors and its overall model is preferred in explaining the variability in the dependent variable. But, in terms of prediction accuracy, ANN are better forecasting methods. Overall these considerations are in accordance with findings reported by Weng et al. (2019) demonstrating the ascendancy of artificial neural networks over traditional methods given the fact they have higher prediction accuracy and faster calculation speed and therefore as well-established methodologies to forecast agricultural commodity price.

Table 6: Forecasting accuracy comparison

\begin{tabular}{|c|c|c|c|}
\hline \multirow{2}{*}{ Measure } & \multicolumn{3}{|c|}{ Methodology } \\
\cline { 2 - 4 } R Squared & MLP & RBF & OSR \\
\hline MAE & 0.812 & 0.856 & 0.896 \\
\hline RMSE & 0.303 & 0.270 & 1.715 \\
\hline
\end{tabular}

MLP: Multilayer Perceptron networks; RBF: Radial Basis Function networks; OSR: Optimal Scaling Regression; MAE: Mean absolute error; RMSE: Root mean square error

Source: Authors' own computations

\section{Conclusions}

This paper proposes to forecast the price of agriculture commodities by using inputoutput pricing model based on ecological-economic approach. For that purpose, we comprehensively discern internal factors as well as external forces that have an influence on production and trade of commodities products. Those factors are interconnected and may include social factors (values, institutions), environmental factors (biodiversity, ecosystem) and economic factors (production capacity, business cycle).

To empirically test our model, we select two different methodologies, namely optimal scaling regression with nonlinear transformations and artificial neural networks which are computing systems. In addition, our study paper reflects on worldwide data related to two agriculture commodities prices (cocoa and coffee), production of crops and livestock, emissions of greenhouse gases (GHG) from 
agriculture as well as information related to the price crude oil. Results show that that there exist both linear and non-parametric relationship between price of cocoa and coffee suggesting a cointegration between the two commodities prices in the long run. This bidirectional relationship comes from the fact that commoditydependent countries often use kindred production landscapes and similar supply chain management when dealing with coffee and cocoa. As a results, effect of supply side shocks from one market may be transmitted to the other one. Similarly, our artificial neural networks models as well as optimal scaling regression demonstrate a strong effect of coffee price, oil price and greenhouse gas emissions on cocoa price suggesting an integrated approach including both concrete technological and proactive managerial measures at various levels as well as appropriate economic incentive-based mechanisms accounting for the social and environmental cost in order to palliate the impact of greenhouse gases on the food system. Collectively, our results appear consistent with (Akrofi-Atitianti et al., 2018; Chaudhuri, 2001; Natanelov et al., 2011)

Other interesting finding is related to forecasting accuracy of our different methods. The main conclusion that can be drawn is that optimal scaling regression parameters overall model is better than artificial neural networks in explaining the variability in the dependent variable. But, in terms of prediction accuracy, results show that artificial neural networks perform better are better forecasting methods confirming their primacy as appropriate methodologies to forecast agricultural commodity price.

Despite our research contributions, a number of limitations should be noted. First, we acknowledge the fallibility of input-output analysis which is a 'conventional' model shared with neoclassical environmental and resource economics. Future work can use mixed models as it is widely acknowledged that conventional methodologies (e.g. cost-benefit analysis, input-output approach) provide limited insight that can be complemented by analysis from other sources (e.g. multi-criteria analysis (MCA), deliberative monetary valuation). Moreover, further studies can investigate the relevance of cultural ecosystem services, such as aesthetics, recreation and similar 'non-material' uses of ecosystems. Second, our study relied on annual data, so we acknowledge a small size limitation of our sample. However, given the difficulties in collecting high-frequency data for variables related to climate change and social metabolism, we believe that we have made appropriate use of the available data to understand their impacts on agriculture commodity price modeling. These limitations can provide a good starting point for discussion and further research can step on the contributions of this paper by using more realistic settings to model agriculture commodity prices. 


\section{References}

[1] Ahmadi, M., Behmiri, N. B., \& Manera, M. (2016). How is volatility in commodity markets linked to oil price shocks? Energy Economics, 59, 11-23.

[2] Akhtar, M. K., Wibe, J., Simonovic, S. P., \& MacGee, J. (2013). Integrated assessment model of society-biosphere-climate-economy-energy system. Environmental Modelling \& Software, 49, 1-21.

[3] Akrofi-Atitianti, F., Ifejika Speranza, C., Bockel, L., \& Asare, R. (2018). Assessing climate smart agriculture and its determinants of practice in Ghana: A case of the cocoa production system. Land, 7(1), 30.

[4] Alam, M. R., \& Gilbert, S. (2017). Monetary policy shocks and the dynamics of agricultural commodity prices: evidence from structural and factoraugmented VAR analyses. Agricultural economics, 48(1), 15-27.

[5] Baker, J. S., Havlík, P., Beach, R., Leclère, D., Schmid, E., Valin, H., et al. (2018). Evaluating the effects of climate change on US agricultural systems: sensitivity to regional impact and trade expansion scenarios. Environmental Research Letters, 13(6), 064019.

[6] Banerjee, O., Cicowiez, M., Horridge, M., \& Vargas, R. (2016). A conceptual framework for integrated economic-environmental modeling. The Journal of Environment \& Development, 25(3), 276-305.

[7] Basheer, I. A., \& Hajmeer, M. (2000).

Artificial neural networks: fundamentals, computing, design, and application. Journal of microbiological methods, 43(1), 3-31.

[8] Bishop, C. (1992). Exact calculation of the Hessian matrix for the multilayer perceptron. In: MIT Press.

[9] Black, A. J., Klinkowska, O., McMillan, D. G., \& McMillan, F. J. (2014). Forecasting stock returns: do commodity prices help? Journal of Forecasting, 33(8), 627-639.

[10] Bohl, M. T., Siklos, P. L., Stefan, M., \& Wellenreuther, C. (2020). Price discovery in agricultural commodity markets: Do speculators contribute? Journal of Commodity Markets, 18, 100092.

[11] Brown, B. J., Hanson, M. E., Liverman, D. M., \& Merideth, R. W. (1987). Global sustainability: Toward definition. Environmental management, 11(6), 713-719.

[12] Bruel, A., Kronenberg, J., Troussier, N., \& Guillaume, B. (2019). Linking industrial ecology and ecological economics: A theoretical and empirical foundation for the circular economy. Journal of Industrial Ecology, 23(1), 1221.

[13] Bugmann, G. (1998). Normalized Gaussian radial basis function networks. Neurocomputing, 20(1-3), 97-110.

[14] Busch, T., Bauer, R., \& Orlitzky, M. (2016). Sustainable development and financial markets: Old paths and new avenues. Business \& Society, 55(3), 303329. 
[15] Cafuta, M. R. (2015). Open space evaluation methodology and three dimensional evaluation model as a base for sustainable development tracking. Sustainability, 7(10), 13690-13712.

[16] Camanzi, L., Alikadic, A., Compagnoni, L., \& Merloni, E. (2017). The impact of greenhouse gas emissions in the EU food chain: A quantitative and economic assessment using an environmentally extended input-output approach. Journal of Cleaner Production, 157, 168-176.

[17] Chaudhuri, K. (2001). Long-run prices of primary commodities and oil prices. Applied Economics, 33(4), 531-538.

[18] Chen, J.-H., \& Diaz, J. F. T. (2020). Application of grey relational analysis and artificial neural networks on currency exchange-traded notes (ETNs). Studies in Nonlinear Dynamics \& Econometrics. doi:10.1515/snde-2015-0088

[19] Costanza, R., Cumberland, J. H., Daly, H., Goodland, R., Norgaard, R. B., Kubiszewski, I., \& Franco, C. (2014). An introduction to ecological economics: CRC Press.

[20] Danilov-Danil'yan, V. I., \& Reyf, I. E. (2018). Sustainable Development Within the Norms of the Biosphere's Carrying Capacity. In The Biosphere and Civilization: In the Throes of a Global Crisis (pp. 207-216): Springer.

[21] de Molina, M. G., \& Toledo, V. M. (2014). The social metabolism: a socioecological theory of historical change (Vol. 3): Springer.

[22] Erten, B., \& Ocampo, J. A. (2021). The future of commodity prices and the pandemic-driven global recession: Evidence from 150 years of data. World Development, 137, 105164.

[23] FAO. (2020). The State of Agricultural Commodity Markets 2020.

Agricultural markets and sustainable development: Global value chains, smallholder farmers and digital innovations. doi:https://doi.org/10.4060/cb0665en

[24] FAO (2021). Production \& Emissions - Agriculture.

Retrieved from http://www.fao.org/faostat/en/\#data. Accessed on February 18, 2021.

[25] Fazeli, A., Hassani, H., Mondelli, M., \& Vardy, A. (2020). Binary linear codes with optimal scaling: Polar codes with large kernels. IEEE Transactions on Information Theory.

[26] Fiala, N. (2008). Meeting the demand: an estimation of potential future greenhouse gas emissions from meat production. Ecological economics, 67(3), 412-419.

[27] Frank, S., Havlík, P., Soussana, J.-F., Levesque, A., Valin, H., Wollenberg, E., et al. (2017). Reducing greenhouse gas emissions in agriculture without compromising food security? Environmental Research Letters, 12(10), 105004.

[28] Greenwood, J., Hercowitz, Z., \& Huffman, G. W. (1988). Investment, capacity utilization, and the real business cycle. The American Economic Review, 402417. 
[29] Haile, M. G., Wossen, T., Tesfaye, K., \& von Braun, J. (2017). Impact of climate change, weather extremes, and price risk on global food supply. Economics of Disasters and Climate Change, 1(1), 55-75.

[30] Hannon, B. (2001). Ecological pricing and economic efficiency. Ecological economics, 36(1), 19-30.

[31] Hu, J. W.-S., Hu, Y.-C., \& Lin, R. R.-W. (2012). Applying neural networks to prices prediction of crude oil futures. Mathematical Problems in Engineering, 2012.

[32] Huang, J., Li, Y., Zhang, H., \& Chen, J. (2020). The effects of uncertainty measures on commodity prices from a time-varying perspective. International Review of Economics \& Finance, 71, 100-114.

[33] Kaufmann, R. K., \& Cleveland, C. J. (1995). Measuring sustainability: needed-an interdisciplinary approach to an interdisciplinary concept. Ecological economics, 15(2), 109-112.

[34] Leontief, W. (1987). Input-output analysis. The new palgrave. A dictionary of economics, 2(1), 860-864.

[35] Louche, C., Busch, T., Crifo, P., \& Marcus, A. (2019). Financial markets and the transition to a low-carbon economy: Challenging the dominant logics. Organization \& Environment, 32(1), 3-17.

[36] Madhiarasan, M., \& Deepa, S. (2017). Comparative analysis on hidden neurons estimation in multi layer perceptron neural networks for wind speed forecasting. Artificial Intelligence Review, 48(4), 449-471.

[37] Mahdavi, S., \& Zhou, S. (1997). Gold and commodity prices as leading indicators of inflation: Tests of long-run relationship and predictive performance. Journal of Economics and Business, 49(5), 475-489.

[38] Maltais, A., \& Nykvist, B. (2020). Understanding the role of green bonds in advancing sustainability. Journal of Sustainable Finance \& Investment, 1-20.

[39] Maurice, N., \& Davis, J. (2011). Unravelling the underlying causes of price volatility in world coffee and cocoa commodity markets.

[40] McCulloch, W. S., \& Pitts, W. (1943). A logical calculus of the ideas immanent in nervous activity. The bulletin of mathematical biophysics, 5(4), 115-133.

[41] Melichar, M., \& Atems, B. (2019). Global crude oil market shocks and global commodity prices. OPEC Energy Review, 43(1), 92-105.

[42] Memarian, H., \& Balasundram, S. K. (2012). Comparison between multi-layer perceptron and radial basis function networks for sediment load estimation in a tropical watershed. Journal of Water Resource and Protection, 4(10), 870.

[43] Mercioni, M., Tiron, A., \& Holban, S. (2019). Dynamic Modification of Activation Function using the Backpropagation Algorithm in the Artificial Neural Networks. IJACSA) International Journal of Advanced Computer Science and Applications, 10(4).

[44] Meulman, J. J., van der Kooij, A. J., \& Duisters, K. L. (2019). ROS Regression: Integrating Regularization with Optimal Scaling Regression. Statistical science, 34(3), 361-390. 
[45] Meulman, J. J., Van der Kooij, A. J., \& Heiser, W. J. (2004).

Principal components analysis with nonlinear optimal scaling transformations for ordinal and nominal data. The Sage handbook of quantitative methodology for the social sciences, 49-72.

[46] Munda, G. (1997). Environmental economics, ecological economics, and the concept of sustainable development. Environmental values, 6(2), 213-233.

[47] Narayan, S. (1997). The generalized sigmoid activation function: Competitive supervised learning. Information sciences, 99(1-2), 69-82.

[48] Natanelov, V., Alam, M. J., McKenzie, A. M., \& Van Huylenbroeck, G. (2011). Is there co-movement of agricultural commodities futures prices and crude oil? Energy Policy, 39(9), 4971-4984.

[49] Nishisato, S. (2014). Elements of dual scaling: An introduction to practical data analysis: Psychology Press.

[50] Parlos, A. G., Fernandez, B., Atiya, A. F., Muthusami, J., \& Tsai, W. K. (1994). An accelerated learning algorithm for multilayer perceptron networks. IEEE Transactions on Neural Networks, 5(3), 493-497.

[51] Paschke, R., \& Prokopczuk, M. (2010). Commodity derivatives valuation with autoregressive and moving average components in the price dynamics. Journal of Banking \& Finance, 34(11), 2742-2752.

[52] Pi, S. M., Liao, H. L., Liu, S. H., \& Liu, D. K. (2011). Using Artificial Neural Network to Filter Spam for Chinese Mail. Paper presented at the Applied Mechanics and Materials.

[53] Reay, D. (2019). Climate-Smart Chocolate. In Climate-Smart Food (pp. 6979): Springer.

[54] Schoenmaker, D., \& Schramade, W. (2018). Principles of sustainable finance: Oxford University Press.

[55] Serletis, A., \& Xu, L. (2019). The ethanol mandate and crude oil and biofuel agricultural commodity price dynamics. Journal of Commodity Markets, 15, 100068.

[56] Sietsma, J., \& Dow, R. J. (1991). Creating artificial neural networks that generalize. Neural networks, 4(1), 67-79.

[57] Somers, R. H. (1962). A Similarity between Goodman and Kruskal's Tau and Kendall's Tau, with a Partial Interpretation of the Latter. Journal of the American Statistical Association, 57(300), 804-812.

[58] Spash, C. L., \& Aslaksen, I. (2015). Re-establishing an ecological discourse in the policy debate over how to value ecosystems and biodiversity. Journal of environmental management, 159, 245-253.

[59] Traoré, F., \& Badolo, F. (2016). On the co-movement between coffee and cocoa prices in international markets. Applied Economics, 48(40), 3877-3886.

[60] Vaast, P., Harmand, J.-M., Rapidel, B., Jagoret, P., \& Deheuvels, O. (2016). Coffee and cocoa production in Agroforestry - a climate-smart agriculture model. In Climate change and agriculture worldwide (pp. 209-224): Springer.

[61] Voora, V., Bermúdez, S., \& Larrea, C. (2019). Global Market Report: Cocoa: JSTOR. 
[62] Wang, Y., Wu, C., \& Yang, L. (2014). Oil price shocks and agricultural commodity prices. Energy Economics, 44, 22-35.

[63] Weng, Y., Wang, X., Hua, J., Wang, H., Kang, M., \& Wang, F.-Y. (2019). Forecasting horticultural products price using ARIMA model and neural network based on a large-scale data set collected by web crawler. IEEE Transactions on Computational Social Systems, 6(3), 547-553.

[64] Willems, S., Fiocco, M., \& Meulman, J. J. (2017). Optimal scaling for survival analysis with ordinal data. Computational Statistics \& Data Analysis, 115, 155-171.

[65] World Bank (2021). Annual prices (Commodity Markets). Retrieved from http://pubdocs.worldbank.org/en/226371486076391711/CMO-Historical-

Data-Annual.xlsx. Accessed on February 18, 2021.

[66] Xiong, T., Li, C., \& Bao, Y. (2018). Seasonal forecasting of agricultural commodity price using a hybrid STL and ELM method: Evidence from the vegetable market in China. Neurocomputing, 275, 2831-2844.

[67] Zafeiriou, E., Arabatzis, G., Karanikola, P., Tampakis, S., \& Tsiantikoudis, S. (2018). Agricultural commodities and crude oil prices: An empirical investigation of their relationship. Sustainability, 10(4), 1199.

[68] Zhang, R., Nie, F., \& Li, X. (2018). Feature selection under regularized orthogonal least square regression with optimal scaling. Neurocomputing, 273, 547-553.

[69] Zhang, Y., \& Na, S. (2018). A novel agricultural commodity price forecasting model based on fuzzy information granulation and MEA-SVM model. Mathematical Problems in Engineering, 2018. 